Comparative Philosophy Volume 8, No. 2 (2017): 65-89

Open Access / ISSN 2151-6014

www.comparativephilosophy.org

\title{
MOVING, MOVED AND WILL BE MOVING: ZENO AND NĀGĀRJUNA ON MOTION FROM MAHĀMUDRĀ, KOAN AND MATHEMATICAL PHYSICS PERSPECTIVES
}

\author{
ROBERT ALAN PAUL \\ (c) Copyright, Robert Alan Paul, 2017, All rights reserved
}

\begin{abstract}
Zeno's Arrow and Nāgārjuna's Fundamental Wisdom of the Middle Way (Mūlamādhyamakakārikāa, $M M K)$ Chapter $2(M M K / 2)$ contain paradoxical, dialectic arguments thought to indicate that there is no valid explanation of motion, hence there is no physical or generic motion. There are, however, diverse interpretations of the latter text, and I argue they apply to Zeno's Arrow as well. I also find that many of the interpretations are dependent on a mathematical analysis of material motion through space and time. However, with modern philosophy and physics we find that the link from no explanation to no phenomena is invalid and that there is a valid explanation and understanding of physical motion. Hence, those arguments are both invalid and false, which banishes the MMK/2 and The Arrow under this and derivative interpretations to merely the history of philosophy. However, a view that maintains their relevance is that each is used as a koan or sequence of koans designed to assist students in spiritual meditation practice. This view is partly justified by the realization that both Nāgārjuna and Zeno were likely meditation masters in addition to being logicians. The works are, therefore, not works that should be assessed as having valid arguments and true conclusions by the standards of modern analytic philosophy-contrary to some of the literature-but rather are therapeutic and perhaps more appropriately considered as part of an experientially focused philosophy such as existentialism, phenomenology or religion.
\end{abstract}

Keywords: Buddhism, comparative philosophy, mathematical physics, Nāgārjuna, soteriology, motion, philosophy, Zeno

\section{INTRODUCTION}

\subsection{SUMMARY}

The context of this paper is a larger project involving examination of "ancient wisdom" as the non-conceptual insights and realizations achieved by meditation

PAUL, ROBERT ALAN: Dalhousie University, Canada. Email: rapaul@dal.ca 
masters of the past which may have enduring relevance, compared with the logical, philosophical arguments and explanations, which I view as historically and culturally relative. I suggest that those arguments, etc. generally require revision into our modern context, since we generally use different concepts, logic, and scientific understanding. I define the 'modern context' as reliance on $21^{\text {st }}$ century analytic philosophy, science, philosophy of science and logical clarity in argumentation, if not formal logic. ${ }^{1}$

I examine Zeno's Arrow and MMK/2 in some detail below. For this introduction, suffice it to say that each suggests that either 'movement' is impossible, or perhaps that understanding of 'movement' is impossible. 'Movement' is yet to be defined. However, the arguments are expressed as if such movement is spatio-temporal movement of physical entities. This may be a metaphor for some more generic kind of movement, and we discuss that more fully below.

For now, consider the more literal expressions: The Arrow states that since at any moment of time an inflight arrow is in only one location, it is not moving in that moment, and therefore, since the entire flight is the simple sum of such moments, it does not move at all. MMK Chapter 2 has many arguments that seem to deny the existence of movement in various forms and for various reasons, but the first verse and some that follow express arguments similar to the Arrow. There are several interpretations we can conclude as the meaning or intent of these arguments:

a. Literal Ontologic Interpretation: The arguments could be a denial that anything physical moves in space and time. This would certainly support the label as 'paradox', since we can directly experience movement. This view is easily argued against, and has been with aplomb and humor by Shimony (in Salmon 1970) and Mabbett (1984) in their little vignettes of a lion moving towards Zeno or arrow fired at Nāgārjuna (anachronistically by Zeno), respectively, and each of them refusing to move since movement is impossible. Any rational person cannot easily defend a literal interpretation of 'movement' as the change of spatial position of a physical entity over time. Hence, in order to use the literal interpretation, we need to approach an understanding of 'movement' in a more deeply philosophic way, considering that term or the entire argument as metaphor.

b. Epistemic Interpretation: Zeno's four paradoxes have been interpreted together as arguments against any rational, analytic, philosophical understanding of the nature of space and time in any of the four options of continuous or discrete space and continuous or discrete time (Siderits and O'Brien 1976 following Brumbaugh 1964). Nāgārjuna's MMK chapter 2 has arguments against the atomistic/discrete nature of space and time, consistent with the generally accepted interpretation that MMK opposes the atomistic philosophies that had been common in his time. However, it also can be viewed as arguments against a continuous space and time. This is reasonable, considering the fact that we really didn't have the conceptual apparatus to

\footnotetext{
${ }^{1}$ In a sense, my use of the term 'modern context' to include analytic philosophy is perhaps redundant, since the latter can be interpreted to be the same as what I define as the former. I comment on this below.
} 
understand continuity until Newton and Leibniz invented calculus, and even when Weierstrauss, Dedekind and others refined it. The conclusions of the ancient arguments do not, however, usually entail that we therefore need more mathematical technology to understand the nature of space and time in these options. That would be a modern conclusion (if it were not for the fact that we do have the math). For Zeno and Nāgārjuna, the common conclusion drawn is that since there is no understanding, that no understanding is possible, hence there is no real space and time, and therefore no real movement. Again, 'movement' may be physical, or movement of consciousness through samsara, or a more generic change or pluralism. Regardless of what kind of movement we are considering, this conclusion is also easily argued against, but has not been acknowledged in the Buddhist philosophic literature and therefore such arguments are offered here as a contribution of this paper.

Recall that in this paper I am concerned with determining what interpretation is true to reality as we know it today, not simply true to the intention of Zeno and Nāgārjuna. It may be the case that both Zeno and Nāgārjuna had either the literal or the epistemic interpretations in mind. However, if that is the case, I then point out counter arguments to indicate that these interpretations do not hold analytic water in the modern context.

In summary (with more detail below), my arguments against the Epistemic Interpretation being true in the modern context are, first, that inference from the lack of rational, analytic, philosophic understanding does not entail the lack of true existence of a phenomenon (rather, it indicates we need better understanding). The inference from no explanation to no phenomena I label Eleatic Logic after Zeno of Elea. Second, we have good, rational, analytic, philosophic, and mathematical physics understanding of physical motion through space and time in any of the four options; and finally, our current, best, empirically justified physics theories state unequivocally that space and time are both continuous, hence we need not even consider the other three options. The first two of my arguments are fairly uncontroversial, but the last may be controversial. However, it is not even necessary in light of the other two, but is just put forth to simplify matters. If it rather muddies the waters for the reader, we can discard it.

c. Property-Nature Ontologic Interpretation: Here movement is a placeholder for any characteristic. In this common interpretation, the MMK arguments could be and have frequently been interpreted to deny svabhāva of anything in nature or mind. Hopkins (1996, 36) lists 17 synonyms for svabhāva or the 'self-nature of phenomena' including inherent existence, ultimate existence, true existence, existence as its own reality, natural existence or existence by way of its own character, substantial existence, objective existence, and existence through its own entitiness. This traditionally is expressed as characteristics, properties, or essential nature that is independent, singular or permanent. The middle way Buddhist philosophy (mādhyamaka), of which MMK is a part, generally, and MMK specifically, deny that there are such things. MMK therefore examines many concepts and phenomena and argues against any substantial existence. In terms of motion, there is a relationship between motion and what is being moved. Part of the issue with the property-nature interpretation is reification, i.e., when we reify motion, for example, it becomes a permanent, essential property. Yet how can movement exist as such a property when 
the object has stopped moving? Hence, reification of properties into svabhāva substance is problematic in the MMK view.

We find many different kinds of arguments within MMK generally, and even within just chapter 2 . I categorize many of these below in what I call 'interpretation clusters'. I argue that most of the common interpretations of chapter 2 and Zeno's Arrow are dependent on the Literal Ontologic or the Epistemic Interpretations described above, which I lump into a single category below. Since those arguments do not withstand analysis under the modern contextual microscope, this is a problem, and we must move on to other interpretations if we are to maintain the modern relevance of these works.

\subsection{ELEATIC LOGIC}

Many Buddhist teachings over the millennia argue using Eleatic Logic, which is a variety of rationalist in contrast with empirical logic. By 'rationalist' I refer to the aspect of many arguments in Buddhist teachings (and even in modern Western metaphysics) that fail to demonstrate sufficient respect for empirical science, but rather promote the view that a 'logical' argument based on 'commonsense' entails a 'true' conclusion about the physical world. In this particular instance, my use of the term is restricted to the Eleatic Logic of arguing from the lack of an explanation to the unreality of a phenomenon. An empirical-based argument would observe the reality of the phenomena, recognize that we have no good explanation, and then proceed to try to devise one.

When Eleatic Logic is applied to phenomena of the physical world, paradoxes of explanation leave us scratching our heads about the illusory quality of what we perceive - are they real, or not? However, there are many more and diverse interpretations of many of these teachings, and it is not clear that we are stuck in a rationalist logic, although it is at least superficially discussed this way. Vasubandhu's 'Proof of Idealism' is an example from Nāgārjuna's era, where our lack of understanding follows to a cittamatra conclusion that everything is mind: "Therefore, atomic distinctions must be supposed and that (atom) is not proven to be simple. It being unproven, it is not proven that forms, etcetera, are the objects of the eye, etcetera. Thus, it is proven that they are mere perceptions" (Kapstein 1988, 51). From analysis of the fallacies in atomic views in Abhidharma, Vasubandhu concludes not just that our analysis of atomic views has flaws, but that there are no simple atoms. Since atoms are supposed to be the building blocks of all entities, he concludes that such entities have no substantial existence (svabhāva), and that they and all matter are mere perceptions, without objective reality separate from perception and mind. This is a major example of how Buddhist philosophers grapple with the problems of atomistic philosophy, while at the same time not having the mathematical techniques necessary to understand its alternative, continuity.

Many contemporary teachers, such as Khenpo Tsultrim Gyamtso, Rinpoche, express a similar view as things not being real because they don't stand up to 
analysis. In his commentary on the opening homage to MMK (Gyamtso 2003), Ari Goldfield (the translator, under Khenpo's guidance) interprets the last line as "I prostate to the perfect Buddha, the supreme of all who speak, Who completely dissolves all fabrications and teaches peace" (Gyamts 2003, 1). Gyamtso's commentary is that

...all of the phenomena of samsara and nirvana are dependently arisen mere appearances, and that therefore their true nature transcends the concepts of arising and ceasing, of permanence and extinction, of coming and going, and of being one thing or different things. In fact, essential reality (dharmata) transcends all conceptual fabrications... Suffering comes from taking things to be real... (Gyamtso 2003, 1-2)

A common interpretation of $\mathrm{MMK}$ is that it is promoting the idea that there is no rational, analytic, philosophical understanding of any concept, thus all phenomena are illusory, or don't exist ultimately.

Again, Chapter 2 addresses motion in a way that is similar to Zeno's four paradoxes, beginning with the first verse that is very similar to the Arrow. Does this mean that Nāgārjuna is advocating for the non-existence of motion? This would be the case only if we interpret 'non-existence' as 'lacking svabhāva'. Hence, motion is real, by at least many of our standard definitions: "not artificial, fraudulent, or illusory... occurring or existing in actuality... existing as a physical entity... having objective independent existence" (Real 2011). The last option and some others I didn't quote bring us to the classic definition of svabhāva as independent, singular and permanent. Hence, in this definition it may be legitimate to say that nothing is real, since the emptiness (śünyatā) doctrine of mädhyamaka is fundamentally the denial that anything has svabhāva. However, common usage (in my estimate as a competent speaker of English) is that we accept real things even though they may be interdependent with other things, composite and impermanent. Yet, this opens us up to many philosophical problems: how do we even identify anything if it is interdependent with other things, made of other things, and changes one moment to the next? How can we even think that such a thing exists at all? Here, then, is at least one modern understanding of the core issues raised by MMK.

\subsection{ZENO AND NAGARJUNA}

Several authors have compared and contrasted Zeno's paradoxes and Nāgārjuna's MMK Chapter 2. ${ }^{3}$ Both similarities and differences have been identified. However,

\footnotetext{
${ }^{2}$ This is, of course, consistent with work by such as Shantarakshita (Padmakara 2005), who analyzes wholes and parts in the neither one nor many argument to conclude that things transcend the concept of parts. "Real", in the sense of Gyamtso, indicates the classical attribution of svabhāva, as 'truly real', or 'absolutely or ultimately real' as permanent, singular and independent. Since (according to mädhyamaka) there are no such things, nothing is real. However, this is a straw man. Nowadays, we are fine saying that things are real, but interdependent, impermanent and composite.

${ }^{3}$ Bhattacharya (1980) suggests the first to identify 'a parallelism' between the two was Jacobi in 1911 and the former goes on to cite Ingalis' 1954 characterization of Indian philosophy's method as
} 
there are many interpretations of what each means, and what purpose each had. ${ }^{4}$ This paper is designed as a contribution to that literature.

The common view is that both are discussing physical objects moving in physical space and time as examples of a more generic motion or other characteristics of phenomena and mind's interaction with phenomena. Differences abound in interpreting with what kind of generic motion each is concerned, i.e. in terms of reification of properties. Both may be addressing universal pluralism, i.e. movement of parts in relationship to wholes. Since he argues against such pluralism, Zeno is classed by many as a monist, while Plato/Socrates in Parmenides reports that both are jointly opposed to both monism and pluralism. Nāgārjuna could also be discussing movement of beings through samsara and rebirth, although I argue that this applies to Zeno also. We could adapt MMK language to say that both are looking at generic arising. Nāgārjuna is usually interpreted as defending no views, but attacking them all. I argue that Zeno may be doing the same (although elsewhere I argue that the former has a definite view). We have more of a context for Nāgārjuna's chapter, i.e. MMK and mädhyamaka generally, yet there is no consensus about the meaning of it, let alone the meaning of the MMK as a whole or Madhyamaka as a whole (see below).

We know little about Zeno and have none of his writings. He is well known for four paradoxes of motion, which have inspired hundreds if not thousands of responses. He was a student - perhaps main disciple and adopted son — of Parmenides of Elea in the 400s BCE. All we know of him is reported by others - mostly by Plato in Parmenides, Phaedrus and Sophist; by Aristotle, especially in dispute against his paradoxes; and by historians hundreds of years removed, such as Diogenes Laertes. In Parmenides, in their visit to Athens, Parmenides is the elder ( 60) respected philosopher, Zeno his disciple and at least philosophical son and defender at $\sim 40$, and Socrates near 20 years old. Of Zeno's philosophy, we have some indications by Plato and Aristotle, but nothing systematic, and we really know very little. Of Parmenides', we have several fragments - providing a significant indication of his ideas-yet still inviting speculation. ${ }^{5}$

grammatical while that of the West uses mathematical (with bibliography on this comparison covering 1956-1978), mentioning Zeno and Nāgārjuna examples. (see citations in Bhattacharya). Siderits and O'Brien (1976) discuss “...the clear correspondence of at least one of Nāgārjuna's arguments against motion to one of Zeno's Paradoxes [the Arrow]..." (281). See also Mabbett (1984), Galloway (1987) and Arnold (2012) for articles addressing the comparison, and many commentaries on the complete translation of the text for such parallelism. For instance, Garfield's (1995) footnote 34 on p.125 says that the "parallels... are evident". Mabbett (1984) cites Jacobi and also Stcherbatsky, Kajiyama and Murti (see Mabbett for citations). Interestingly, Mabbett cites Stcherbatsky as noting that there is "no trace of Nagarjuna having known them (Zeno and Parmenides)". See McEvilley (1981, 1982, 2002).

${ }^{4}$ For example, Siderits and O'Brien write "There is no question but that Zeno and Nāgārjuna put their respective refutations of motion to completely different uses." (281).

${ }^{5}$ For background on Parmenides see Palmer (2016). My main sources were Lombardo (1982) and Kingsley (2003). For background on Zeno see Palmer (2017), Plato's aforementioned dialogues and Aristotle's Physics Book VI, chapter 9 lines 5-9 as examined below. 
Although there is considerable uncertainty in who the writer of MMK was (or even when and where in India he lived) it is consistent with current understanding and teachings by current authorities in Tibetan lineages that teach the mädhyamaka that the author of the first significant philosophical formulation of mädhyamaka after the prajñāpāramitā sutras was named Nāgārjuna and was an Indian Buddhist philosopher of the $1^{\text {st }}-2^{\text {nd }}$ centuries $\mathrm{CE}$ and by legend was also a meditation master. ${ }^{6}$ I will examine the relevance of this legend and lack of firm documentation below.

\subsection{ARGUMENTS ABOUT WHAT?}

In detailed exegetic analysis, attending to examination of the Sanskrit, Chinese and/or Tibetan texts and commentaries, recent Western scholarship has cogently argued that the second chapter of Nāgārjuna's MMK - as interpreted within the context of the entire work and larger Buddhist philosophical literature-primarily concerns the nature of time and space in the physical world, ${ }^{7}$ or that it does not; ${ }^{8}$ that it has metaphysical, epistemic, semantic and/or soteriological intent; ${ }^{9}$ that it is about physical motion and/or action in general, or action as karma in birth and rebirth

6 See Mabbett (1998) for a comprehensive historiography of our uncertainties. See e.g. http://www.rinpoche.com/stories/nagarjunalife.htm for the legend according to current authoritative teachers. MMK has roots in the prajñāpāramitā sutras, and I do not imply that there are any Buddhist teachings that do not have roots in the direct teachings of the Buddha.

${ }^{7}$ Siderits and O'Brien follow Braumbaugh in interpreting Zeno (as a defender and expander of Parmenides' views) as sounding a death knell to the Pythagorean atomism in time and space which was being challenged by the Pythagorean discovery of irrational numbers in mathematics. Their analysis considers all four paradoxes as a comprehensive system, while I focus only on the arrow. More below. Siderits and O'Brien then examine Nagarjuna's work in the context of "Indian notions of space and time" and the "ultimate atom" (286-7) of space (paramāņu) and time, especially in the sāṃkhya, Nyāyá and Sarvāstivāda schools, and mathematics, where rational numbers were also known in the 5th or 6th century BCE. "Our aim is to show that some of Nagarjuna's arguments against motion, like Zeno's Paradoxes, exploit the atomist's assumptions about continuity and discontinuity of space and time" (288). See, however, their footnote 11.

${ }^{8}$ Bhattacharya argues that Nagarjuna's arguments pertain to grammatical issues in Indian logic, rather than what Arnold calls 'geometrical presuppositions'. Westerhoff (2008) does not quite say that Nagarjuna is not addressing physical movement through time and space (that is 'often' the interpretation), but that "it is possible to read Nagarjuna's arguments in the second chapter of the MMK without regarding them as concerned with the structure of space and time. Doing so has a number of advantages" (456). Beyond the justification that the rest of the text or other of the author's extant writings fail to have "any clear claims about the way space and time are structured", alternative interpretations are "more profitable" if we see the text as concerned with properties and instantiating individuals.

${ }^{9}$ This covers a lot of territory, and most analysts come under one or the other (or more than one) of these three categories. See Arnold's (2012), discussion of possible interpretations, especially of Westerhoff's (2009, Chapter 6), and Westerhoff himself, and of Oetke (2011) for different categories of interpretation. Mine can be seen as a mere reworking of their's. Arnold focuses on the metaphysical and epistemic, while Bhattacharya and to a degree Westerhoff focus on the semantic. See also Westerhoff (2008) for a precursor to his (2009), emphasizing the theory of properties, that I place in the inner interpretation cluster, lumping semantic and property-nature interpretations. 
through cyclic existence (samsara) ${ }^{10}$ that it concerns properties and instantiation, the grammar of natural language and its ontological relationship with physical reality; ${ }^{11}$ being and becoming; the nature of explanation; ${ }^{12}$ the possibility of a rational metaphysics; ${ }^{13}$ the non-existence of an extralinguistic reality; ${ }^{14}$ and that it has significant similarities to Zeno's paradoxes, or that it does not. ${ }^{15}$

Encouraged and enticed by the well-known lack of consensus, I identify three interpretation clusters. Very briefly, I label these as outer, inner and secret.

\subsection{INTRODUCTION TO THREE INTERPRETATIONS CLUSTERS}

The outer cluster is highly materialistic and literal (as mentioned previously) relating to space and time as reality (ontic) or our knowledge or explanation of it (epistemic, also as mentioned previously, but here categorized together with the ontic), and is amenable to analysis by mathematical physics. In the case of the literature of Zeno's Arrow, this has been accomplished, i.e. the paradox has been solved and it is paradoxical no more ${ }^{16}$-although occasional grossly inaccurate analysis periodically appears (see below). There are additionally some vaguely plausible objections I discuss below. Hence, in an outer interpretation cluster of MMK 2, which is similar to the outer interpretation of Zeno's Arrow, such analysis would have little importance in the modern context.

The inner cluster indicates interpretations relating to the properties or nature of things, and semantics. The inner cluster pertains to semantics due to the way we

\footnotetext{
${ }^{10}$ See footnote 12 below.

${ }^{11}$ Other footnotes for this paragraph pertain to these.

${ }^{12}$ As many point out, e.g. Mabbett (1984), “...both [Zeno and Nagarjuna] claimed to show the impossibility of giving any coherent logical account of motion" (403). This view-if generalized to be their sole purpose, which many do not agree with - would damn them both to historical irrelevance and obscurity in the light of modern mathematical physics that shows a quite coherent logical account of motion, as discussed in this paper. My contention is that they fail in this purpose, but there are other purposes that (I argue here) are deeper and survive analysis. Arnold cites "Nagarjuna's case against the intelligibility of motion..." (553), suggesting that it is not denying motion, per se, but rather denying our explanation of it (at the time).

${ }^{13}$ This is a generalization of the previous one.

${ }^{14}$ This is what I would argue is a bizarre conclusion that several authors attribute to Nāgārjuna stemming from his conclusion that he could find no rational explanation or understanding of motion, hence there was no motion. I discuss this fully below. I.e., the world doesn't exist because we can't explain it rationally. I doubt that Nāgārjuna thought this, but I don't know his mind, and find it irrelevant to my project anyway.

${ }^{15}$ Most analysts find similarities between Zeno and Nāgārjuna in the mathematical/physical outer interpretation cluster, while it is interesting to note that Mabbett (as mentioned previously) and Westerhoff (2008) consider that Nagarjuna's "... soteriological problems of the subject moving (gati) through transmigratory existence (samsara)" (Westerhoff, 455) are irrelevant to Zeno-contrary to my thesis here.

${ }^{16}$ Salmon's (1970) introduction to his collection of articles lays out much of the proper solution, also available in an adaptation at https://math.dartmouth.edu/ matc/Readers/HowManyAngels/SpaceTime Motion/STM.html. Grünbaum (1967) covers similar material, yet gets rather convoluted in the process. Mazur (2007) comes close and offers a good historical perspective. See my analysis below.
} 
describe the instantiation and/or reification of properties in things, especially as being either innate or interdependent. These actions are so entwined with some languages as to be ingrained habits of mind to the degree that many people barely imagine thinking any other way. Much of the analysis in the inner cluster is dependent or derivative on the success of analysis in the outer cluster. Since there is no outer interpretation paradox anymore in light of modern analysis, much of the inner interpretations also have lost their import in the modern context.

The secret cluster pertains to personal meditative journey, hence is called soteriological, heuristic, or therapeutic. I have not seen any analysis of Zeno in this cluster, while it is frequently pointed out that this is at least one of Nāgārjuna's purposes: "Of course, there is a major difference [between Zeno and MMK verses (kārikās)] which, taking the kārikīs out of their religious context, we may overlook. Nāgārjuna's dialectic is not mere logic, or even mere metalogic. It is heuristic, or therapeutic. Its function is largely to prepare us for meditation or mystic insight" (Mabbett 1984, 403).

Identifying MMK as therapeutic in purpose supports my own analysis, yet while Mabbett acknowledges this purpose, he excludes its relevance to philosophical understanding, focusing instead "to clarify what Nāgārjuna means when he writes about a certain topic" - what I call the exegesis that I am less interested in. However, I argue that identifying MMK as therapeutic does not make it irrelevant to all philosophical understanding, just to understanding by the standards of the modern context, i.e. modern analytic philosophy. That is because MMK has a soteriological purpose independent of the logical validity of its argument and empirical truth of its conclusion. By 'empirical truth' I indicate that Nāgārjuna may have had the intention to present a conclusion that was empirically true - in a correspondence sense of truth to correspond with physical reality - but rather in the modern context the conclusion of the argument - that there is no motion - does not correspond to physical reality.

If - as I will demonstrate - we apply the methods of modern analytic philosophy and find that the arguments of MMK and Zeno's Arrow are not valid and/or are fallacious, and we are left with that possibility that what I am calling the secret interpretation is the one that might make those 'arguments' valid and true, then we might consider those arguments more relevant to other philosophical approaches. ${ }^{17}$ If modern analytic philosophy is coincident with what I call 'the modern context', i.e., "characterized by an emphasis on argumentative clarity and precision, often making use of formal logic, conceptual analysis, and, to a lesser degree, mathematics and the natural sciences" (Analytic philosophy 2017, 1), then perhaps an experiential subdiscipline may be more appropriate, such as existentialism or phenomenology. I will not, however, examine details of those sub-disciplines in application here, but rather approach the secret interpretation through the lens of Buddhist mahamudra. In

\footnotetext{
17 'Arguments' is here in scare quotes because in the secret interpretation we are more concerned with their affect on students, rather than their characterization as logically valid, hence they are not quite arguments, but more like allegories or metaphors.
} 
conjunction with that examination, I will also consider the role of koans in philosophy.

My focus, after gleaning many possible interpretations of the arguments, is to first determine if MMK/2 and Zeno's Arrow are philosophically coherent using modern analytic methods and knowledge of philosophy, logic and science. If we determine that they are not, we can choose to either declare them irrelevant to our times or seek a solution in an alternative interpretation, such as the therapeutic. I argue against the validity of interpretations by Mabbett and other philosophers who interpret MMK outside of the therapeutic context.

Before we examine the interpretation clusters in detail, I provide some further background to the arrow and MMK, Zeno and Nāgārjuna.

\subsection{ZENO'S ARROW}

We know of Zeno's paradoxes only from secondary sources. The main source is Aristotle in Physics, Book VI, chapter 9, lines 5-9, who interprets Zeno in the outer cluster. Aristotle discusses Zeno within a context of an extended discussion of time, change and motion, stating that Zeno's reasoning is fallacious in thinking that anything that occupies a location in space equal to its size is necessarily at rest. Aristotle says that Zeno is mistakenly assuming that time is discrete. Siderits and O’Brien (1976, hereafter S\&O), however, following Brumbaugh (1964), suggest that the four paradoxes each address one of the permutations of discrete or continuous space and time, while the Arrow addresses continuous space and time. Each paradox shows that one of the four options lead to absurdity, hence "[w]hether space and time were atomistic or infinitely divisible, no intelligible account of motion through them was possible" (482).

I have found different assessments in the literature as to which of the four permutations of discrete (atomistic) or continuous, space and time, are being used by Zeno in the Arrow, and by Nāgārjuna in $\mathrm{MMK} / 2$. Both, however, are trying to reduce all permutation to absurdity. Their purposes have been identified as denial of the possibility of (1) motion, (2) any rational metaphysics of motion, (3) pluralism and/or monism, (4) any rational metaphysics of any concept, (5) the reality of any concept, and/or (6) the possibility of any reality whatsoever.

While my argument is not dependent on the fact that science in the modern context identifies both space and time as continuous, ${ }^{18}$ it is important to know that is the case in order to counter comments to the contrary. Some philosophers may object, and suggest that there is currently some ambivalence about the nature of space and time in modern physics theories. Yet, that is not the case. Space and time are both continuous in both of our best theories, general relativity and quantum mechanics, at least in all empirically accessible spaces and times, regardless of the discrete nature of certain measured characteristics of certain entities under certain conditions.

${ }^{18}$ See Paul (2016b), or Bub (1997, 4). 
Relevant to the outer cluster, modern mathematical physics has solved both the Arrow and Nāgārjuna's treatment of the problems of motion, whether we use the differential calculus and the real number line to represent continuous space and time, or use discrete mathematics as we might when we gather real measurements. ${ }^{19}$ The solution is found in using a modern definition of 'motion', as I define below.

It is very easy to apply very elementary arithmetic to the physics of moving things and get completely overwhelmed with apparently contradictory arguments. For example, many analysts still attempt to look at speed as the zero spatial displacement of the arrow when in one location at one time divided by the zero temporal displacement in one instant. They then get zero divided by zero, which is undefined, as support for the paradox. See Papa-Grimaldi (1996) for an example. Thus, they conclude the absurdity of motion from the absurdity of that quotient. This kind of analysis is complete nonsense. When we analyze this 'paradox' using the mature calculus and a definition of motion from mature mathematical physics, we find no paradox at all.

In addition to Aristotle's and Brumbaugh's treatments using the outer interpretation cluster, we also have some insights into Zeno in the early parts of Plato's dialogue Parmenides co-staring Socrates, Parmenides and Zeno. These suggest that the outer and inner interpretation clusters may be overrated, at least, and perhaps completely mistaken. This claim requires some unpacking.

First, how do interpretations of Zeno relate to interpretations of Nāgārjuna, and vice versa? We will see how the first verse MMK/2.1 is very similar to Zeno's Arrow in the outer interpretations, and how the rest of the chapter of the former might be used to explicate that first verse, hence can help in understanding the unspecified complexities that Zeno might have discussed, and later Zeno-analysts did discuss, again while keeping to the outer cluster. Hence, we can see how outer interpretations of Nāgārjuna might assist understanding Zeno, at least if we are very narrow in our focus, and similarly how later analysis of Zeno by ancient and modern philosophers may also help us understand and explicate $M M K / 2$, in the outer cluster.

Yet, when we broaden the focus to understand that Nāgārjuna's inner interpretation cluster to his entire project may be central to the meaning of the chapter and text, have we lost any connection with Zeno? I argue that we haven't. There is no reason to believe that Zeno's Arrow is simply about an Arrow, just as Plato's Cave is certainly not about a cave. Applying the inner cluster of MMK to Zeno, the arrow is a metaphor for a larger set of philosophical issues, including movement as a property of an object, and instantiation/reification in our language customs. There is no reason not to take these interpretations as hidden meanings of Zeno's Arrow, and I will do so.

When we further broaden the significance of MMK to the secret or soteriological/therapeutic cluster, which has been said by many to be the actual significance and purpose of the philosophical treatise, then we will have to take a leap

\footnotetext{
${ }^{19}$ I offer the conjecture that the Doppler-redshift method described below to measure velocity can be done with continuous data with analog measurements not requiring discrete sampling.
} 
into a secret interpretation of Zeno's Arrow if we are to find some inter-utility. This, however, is the core purpose of my essay.

\subsection{PARMENIDES AND ZENO}

We see from Plato's Parmenides, that Zeno is one of, if not the most direct disciple and main philosophic student of Parmenides. We must remember that philosophy in those days was not distinct from religion. ${ }^{20}$ In the parlance of the third interpretive cluster, he is Parmenides' spiritual heir. This relationship suggests that the practices and resulting viewpoints of Parmenides - as attributed to him by Kingsley and Lombardo-were also practiced and shared by Zeno. Therefore, we might be well advised to interpret his paradoxes in this light. This brings us to the secret interpretation cluster for Zeno, which then we can see corresponds to the secret interpretation cluster for $\mathrm{MMK} / 2$.

Socrates comments that Zeno is as opposed to plurality as to monism. ${ }^{21}$ This demonstrates further similarities between Zeno and Nāgārjuna in their method of arguing by reduction against all views. It may even be that they have similar purposes, contrary to most assessments.

How does this dialogue relate with Zeno's paradoxes? Nick Hugget's (2010) article suggests that the pluralist approach is to examine parts, which have parts, etc., yielding infinite spatial parts that cannot result in a finite distance - the classical view that is contrary to our modern context. But this is the outer, and perhaps somewhat inner interpretation cluster view.

In the context of the third interpretation cluster as informed for Zeno's Arrow by Kingsley (2003) and Lombardo (1982), and for MMK by such as Mabbett, Conze, Gyamtso and many more, when we look closely at Parmenides' fragments and consider how MMK is used in some teachings, we can interpret the monistic 'one' to represent pristine, non-conceptual awareness (jūanna or perhaps rigpa ${ }^{22}$ ) that does not change, hence exhibits stability, while the pluralist 'many' represents thoughts and emotions, wholesome and unwholesome (kleśa), that come and go within that stable stillness. Hence, the arrow's movement is a metaphor for movement of mind. Such movement is observed, yet we also experience the stillness of mind. By analysis we cannot have both, hence we have a paradox designed as a koan to interrupt fixation on rational philosophy.

\footnotetext{
${ }^{20}$ See Lombardo (1982/2010, vii).

${ }^{21}$ Consider similariries to the Madhyamaka neither one nor many argument. That classical Buddhist argument is found in detail in Sāntarakșita's Madhyamakalankara, Adornment of the Middle Way (Padmakara 2005).

22 "The omniscient eye of pristine awareness is an eyeball looking in all directions simultaneously, in the total 360 degree vision of the holistic seed, the source of space-time in the zero dimension. In rigpa, no temporal processes take place; there is no motion..." (Longchenpa's Precious Treasury of Natural Perfection / Keith Dowman) It is also called 'spontaneous presence'; jñāna is also pristine awareness. All these terms might apply to the fruition of incubation-hard to judge which, since there aren't too many practicing Pythagorans to tell us.
} 
We might ask whether koans have any place in a philosophical discussion if the purpose of koans is to interrupt fixation on rational philosophy, or to even interrupt fixation on rational thought altogether. Here is where we must distinguish modern analytic philosophy - highly focused on rationality as it is - from more experiencefocused philosophy, perhaps existentialism or phenomenology. The reader is therefore invited to bring in both the rational analytic and experience-based philosophic literature on emotions, insight, will, belief and consciousness of a living person, along with religious philosophy, in all of which consideration of koans belong. I, however, do not accept that broad scope invitation here, but rather consider koans in a limited context of the experience of mahamudra meditation practice, as discussed below.

Lombardo and Kingsley associate Parmenides with the Greek shamanistic tradition elaborated in more detail by Kingsley. Parmenides' poem portrays "that the universe and our minds form a mutually committed whole" (Lombardo 1982, vii), which reminds us of the Vedic view of microcosm in the body reflecting macrocosm of the universe.

Lombardo hypothesizes that Empedocles and Parmenides "trained themselves in some kind of formal meditation practice, perhaps Pythagorean in origin, and that there are hints of what this was in the fragments" (viii). Kingsley elaborates the practice as what was called 'incubation', a retreat in a completely dark cave for an extended period of time, even as long as a year. During this meditation, the spirit migrates to the underworld - which can be interpreted as death of the self-centered ego that interprets everything in terms of its own edification. Once ego is destroyed during this dark retreat, in the Buddhist terminology the person can become fully realized to the innate compassion and wisdom of original mind.

In the underworld, according to his poem, Parmenides' spirit received instruction in the nature of reality from 'the Goddess'. In the eighth fragment, Parmenides recites the Goddess' instructions on the road to "WHAT IS": "There is only one tale of a path left to tell: that is. And along this way there are many, many signs that as well as being birthless it is also deathless and whole and of a single kind and unmoving - and neither is it incomplete" (Kingsley 2003, 160).

Here we find the roots of Zeno's paradoxes, to establish that motion is impossible. But it is not the motion of an arrow that is impossible. Rather, it is the plurality of the world, while its physical unity is embodied in the single all-encompassing physical universe, and its spiritual unity in spontaneous presence (Tib: lhündrup); it is being without attachment in the present moment, rather than lost in thought about past and future, or even being attached to what is happening in the present moment - also called the fourth moment, ${ }^{23}$ awareness uncluttered by ego. "Wherever it seems that

\footnotetext{
23 "Beyond Present, Past, and Future Is The Fourth Moment.....totality is taking place. A very precise something or other is happening. That is the state of vipashyana. It is nonverbal and nonconceptual and very electric. It is neither ecstasy nor a state of dullness. Rather, a state of "hereness" is taking place, which is described in the Tibetan Buddhist literature as nowness." Trungpa Rinpoche, $<$ http://www.shambhalasun.com/index.php?option=com_content\&task=view\&id=2883\&Itemid=0 $>$.
} 
you go, or come, everything happens in your consciousness. And that consciousness never moves, is always the same"24 (Kingsley 2003, 80).

Now we can access the experience, insights, concepts and terminology of Buddhist Mahāmudrā teachings. ${ }^{25}$ Lack of motion is stability of mind, which is realization of the Buddhist calm abiding (śamatha) meditation practice. Hence, the arrow is a mere metaphor for the mind that is always immovable, while thoughts of distant lands pop up and blow away. The mind as the ocean of awareness of thoughts rests in stability, even while there are ripples and waves of movement of thoughts or emotions that are self-liberated into their own luminous nature as awareness becomes aware of them. It is the unity of plurality and monism as the unity of mental movement within stillness.

\subsection{NAGARJUNA'S ARROW}

There are several examinations of $\mathrm{MMK} / 2$, and the reader is invited to look at those for more complete analysis. I merely scratch the surface here to make my point.

Here we just look at the first verse, as the core expression of similarity with Zeno:

MMK 2.1

$(\mathrm{S} \& \mathrm{~K})$

Gatạ̣ na gamyate tāvadagatam naiva gamyate

gatāgatavinirmuktạ̣ gamyamānaṃ na gamyata

Just as the path traversed is not being traversed, neither is the path not yet traversed being traversed. The path presently being traversed that is distinct from the portions of path traversed and not yet traversed is not being traversed. (32)

(Garfield, 1995)

What has been moved is not moving.

What has not been moved is not moving.

Apart from what has been moved and what has not been moved,

Movement cannot be conceived. (6)

(Gyamtso, 2003)

On the path that has been traveled, there is no moving.

On the path that has not been traveled, there is no moving either,

And in some other place besides the path that has been traveled and the path that has not,

Motions are not perceptible in any way at all. (13)

\footnotetext{
24 "Wherever you go, there you are", Buckeroo Bonzai (movie).

25 These can be found in texts by Wangchuk Dorje, e.g. (2001), and commentaries by Khenchen Thrangu, Rinpoche (2003, 2004) and Tenzin (2014).
} 
The similarity to Zeno is clear on the outer/ontic interpretation cluster. In that cluster, this verse establishes the initial supposition that motion (or at least the rational understanding of it) cannot be possible in any of the three times. That is how S\&K, S\&O and Gyamtso (hereafter, Khenpo, Rinpoche) interpret the verse. Garfield and Kalupahana, however, immediately interpret this verse in terms of the reified inherent nature of my inner (semantic/property nature) interpretation cluster. Yet, the inner is dependent and derivative of the outer: since there is no movement in the past or future, the object didn't move and will not move, hence doesn't now move, hence there is no inherent property of movement in the object.

The target of Nāgārjuna's arguments in this chapter is any view of motion according to which motion is an entity, or a property with an existence independent of that of moving things, or according to which motion is part of the nature of moving things. (Garfield, $1995,124)$

This is in the inner cluster. However, to establish this, Garfield begins his commentary of the first verse with the outer interpretation:

That is, if motion exists, there must be sometime at which it exists. Nāgārjuna in this opening verse considers the past and the future. This makes good sense. For motion requires a change of position, and a change of position must occur over time. But the present has no duration. So if motion were to exist, it would have to exist either in the past or in the future. But a thing that has moved only in the past is not now moving. Nor is a thing yet to be moved. (125)

The other interpreters examine other verses and chapters in similar fashion to Garfield and Kalupahana on this verse; hence the inner interpretation cluster is generally the favorite, yet the outer interpretation must be applied to establish the ground of the inner.

Hence, the logical validity of the inner cluster is largely based on the scientific and mathematical validity of the initial paradox in the outer interpretation-and I argue that there is none, i.e. there is no scientific and mathematical validity, no paradox, and the object moves in all three times (see below). Hence, there is no logical validity of the inner cluster, even though the conclusion may or may not be true (that there is no inherent nature), since it is outside the scope of the outer interpretation. It is just the argument for it that is invalid.

As mentioned, Aristotle and others suggest that Zeno is using infinitesimals to argue for his paradox that concludes there is no motion. Aristotle argues against Zeno by appeal to continuous space and time, and most modern mathematical-scientific treatments of Zeno's Arrow follow Aristotle to show that motion in the outer cluster exists, by using the calculus (see below). Commentary on MMK usually places it in the context of a critique of atomism. Nāgārjuna's arguments against atomism use a rudimentary understanding of continuity, which is the major classical alternative. However, commentary typically fails to point out that his arguments display a lack of understanding of continuity. His arguments do not entail valid denials of continuity as 
used in modern mathematical-scientific treatments, although many analysts seem to argue that they do.

Different verses of $\mathrm{MMK} / 2$ are interpreted to examine different assumptions of discrete or continuous space and time, just as Brumbaugh (1964), Battacharya (198081 ) and $\mathrm{S} \& \mathrm{O}$ argue that Zeno is examining them in different paradoxes. Regardless of the use of discrete or continuous space and time, the analysis fails to hold up to modern scrutiny.

In the next section I will examine each interpretation cluster in more detail. I will also demonstrate how modern mathematical physics denies the outer interpretation cluster, and with it justification for the inner. We will be left with the secret, unless we wish to banish both of those philosophers to the confines of merely historical relevance.

\section{THREE INTERPRETATION CLUSTERS}

\subsection{OUTER-PHYSICAL MOTION INTERPRETATION CLUSTER}

The ontic aspect of the outer interpretation cluster includes what Westerhoff calls the spatio-temporal, what $\mathrm{S} \& \mathrm{O}$ calls the mathematical, and what most analysts at least begin their examination of the chapter. This is the interpretation that $M M K / 2$ concerns paradoxes of physical motion that demonstrate how such motion is not

possible. The epistemic aspect of the outer interpretation combines what Arnold (2012) calls a concern with explanation and many identify as concern with denial of metaphysics altogether. The core of the epistemic view is that any reasonable sounding understanding or explanation of motion results in absurdity.

This epistemic conclusion has consequences relating to the ontic interpretation of this cluster, connected by what I call the Eleatic Logic that the lack of a rational explanation of a phenomenon entails that the phenomena lacks some sense of 'reality', i.e. motion is not possible if we don't understand it. Many Greek, Indian, Tibetan and Western philosophers - ancient and contemporary-argue based on this connection. I label them 'rationalists'. The argument is, of course, senseless to modern empiricists, scientists and most Western analytic philosophers.

Both Zeno's Arrow paradox and the MMK/2 textual arguments, as interpreted in the outer interpretation cluster, are not coherent in the modern context, because (a) the logic is fallacious, in that even though motion was not understood for most of history it still was a real phenomenon, and (b) the premise is false in the modern context, in that we now have a complete and valid explanation and understanding of motion (see below). Hence, there is no reason to think that motion is illusory in any regard, although it is of course dependent on the things that move.

Following, yet enhancing, Salmon's introduction to his (1970) we can utilize modern mathematical physics with a modern definition of motion and find no vagueness, paradox or absurdity. In the modern context, motion at a point is defined as instantaneous velocity. Instantaneous velocity is defined beginning with average 
velocity-but not stopping there. Average velocity does not entail any suggestion of vagueness: first the arrow is at the bow, later the arrow is in the tree. Neither does instantaneous velocity entail vagueness, since it is the limit of the sequence of average velocities as the intervals get smaller and approach the point in question, and not actually one of the average velocities.

At most points in the flight of an arrow, average velocity is the simple ratio of distance to time in a specified spatial and temporal interval. Consider an inflight interval that includes a particular point $\mathrm{P}$ where we want to know the instantaneous velocity, the motion at point $\mathrm{P}$. There are two ways to measure velocity at a point. First, we may use Doppler-redshift technology, similar to getting the velocity of stars. This might even be made continuous, rather than point-by-point. This is a perfectly valid technique, available for 100 years. This can also be used at the endpoints of flight.

Alternatively, we might use techniques that have been available for 400 years: We start with an arbitrary interval containing that point, and then simply reduce the distance and time interval towards that point. We therefore get a series of average velocities $\mathrm{v}_{\mathrm{n}}=\left(\mathrm{x}_{\mathrm{n}+1}-\mathrm{x}_{\mathrm{n}}\right) /\left(\mathrm{t}_{\mathrm{n}+1}-\mathrm{t}_{\mathrm{n}}\right)$ as $\mathrm{n}$ goes from 1 to $\mathrm{N}$, an arbitrarily large number. Since time, space and motion are continuous, eventually (as $n$ increases) we will get to the point in this series where the series is 'smooth', i.e. in the limit for small increments in space and time the series varies little compared with the magnitude of each value $\left(v_{n}-v_{n-1}\right)<<v_{n}$. If we are not at the stopping or starting times, or if no significant change happens, like a rock deflecting the arrow, the series will converge to a value $\mathrm{V}$, the instantaneous velocity at point $\mathrm{P}$. If $\mathrm{P}$ is at one of those deflection points, we must deal with it in different ways (single sided sequence to the point), but there is no problem in doing so. There are standard methods to determine convergence.

Measurements are generally discrete, and these methods refer to the actuality of experiment, not simply the theory of continuous spaces.

Average velocity is never defined at a point in space and time. Only the convergent point limit is defined at such a point, and it is not ever $0 / 0$ for any physical motion. ${ }^{26}$ This definition makes all the difference: motion becomes coherent, and such rational coherence reflects the empirical fact that things move from one place to another, i.e. that motion is real.

In addition to physical motion, the outer interpretation cluster also pertains to contexts of persons 'traveling' through samsara - the sense of change in normal experience of people who are not realized meditation masters-or more general action, change, and agency. However, analyses in this outer cluster typically rely on either the analysis or at least the analogy of denial of physical motion to justify their own various denials of different kinds of motions. To the degree that this is the case, if I am correct in my assessment of interpretations of spatio-temporal objects, then such denial of these different motions is similarly fallacious in the modern context.

\footnotetext{
${ }^{26}$ Salmon's (1970) introduction covers this appropriately. Many previous and even later authors ignore this central nuance.
} 
Since many arguments in the literature do invoke such foundations: "just as with the physical arrow, so also in regard to people, generic change, change of properties or experiential journey', they too are fallacious.

Rather than consign Zeno and Nāgārjuna to merely historical significance, I argue the outer interpretation is a very superficial interpretation of these texts. It seems problematic to presume that either Zeno or Nāgārjuna had such a superficial understanding of their philosophy as that which is demonstrated by the physical motion context of the outer interpretation cluster. After all, it is obvious that the arrow moves from bow to tree, hence there is motion throughout the flight. Only a fool would deny that, as demonstrated by Albert Simony's ${ }^{27}$ vignette of Zeno not getting out of a lion's path because he judges it is impossible for the lion to move, or Mabbett's (1984) vignette of Nāgārjuna not taking cover when Zeno anachronistically fired an arrow at him. Poor, dead Zeno and Nāgārjuna. It is astounding that these vignettes are considered arguments against the paradox and MMK verses, like we consider the authors as idiots. If we give them a little credit for not being idiots, this actually demonstrates not that they made no sense, but rather that our outer interpretations don't make sense. ${ }^{28}$ Luckily, we have other potential interpretations. ${ }^{29}$

\subsection{INNER (SEMANTIC/PROPERTY-NATURE) INTERPRETATION CLUSTER}

The second interpretation cluster in my categories is the inner, or more descriptively the semantic/property-nature interpretation. This has two aspects. The semantic aspect combines interpretations that depend intimately on the semantic use of what Hayes (1994) calls Nāgārjuna's 'equivocation fallacy' and Taber (1998) explicates as 'co-existing counterparts'. In $\mathrm{MMK} / 2$ we find it as the pairs of terms 'mover' and 'moving', and also as the 'locus of motion' and the 'action of motion'. Analysis by Nāgārjuna, at least as interpreted by Candrakīrti in the Prasannapadā (Sprung 1979) and those who rely on the latter, then proceed to demonstrate, for example, the absurdity of having the 'inherent property' of motion in something that is a mover, since it is not such a property when the mover doesn't move. Kalupahana and Garfield make this point in their commentaries. We must remember that the common interpretation of the entire text is that it denies any inherent properties of any sort of

\footnotetext{
27 in Salmon (1970)

${ }^{28}$ Some might accuse me of Whiggishness, by judging sense by today's mathematical physics standards. I reply: First, I am being entirely Whiggish in trying to determine what of this 'ancient wisdom' makes sense today. That is what concerns me. Only historians of philosophy should be interested in what doesn't make sense by today's standards but made sense in historical times using standards of understanding (science and logic) that we have thoroughly discredited today. Second, Eleatic Logic never made sense. It was never sensible to say that if we didn't understand a phenomenon then the phenomenon is unreal, rather than saying that we need to find a good explanation to understand the phenomenon, and the phenomenon right in front of us is obviously real. Third, clearly things move, and that must have been clear to the ancients. What they were trying to do must not have been to deny the reality of physical motion.

${ }^{29}$ For other physical-mathematical interpretations of MMK, see Paul (2013, 2016a, 2016b).
} 
any thing. Closely related to that context is the property-nature aspect of this interpretation as discussed by Garfield (1995) and Westerhoff (2009). The equivocation fallacy is now explained within the view that MMK concerns the nature of properties and their instantiation as reification of an inherent nature. We are told that it is the reification itself that results in paradoxes and absurdity. The purpose of Nāgārjuna's arguments, therefore, is to convince students to realize that when we give up reification, the 'emptiness' of all things is revealed. This is śunyatā, that all things are empty of inherent nature. In this interpretation cluster of $\mathrm{MMK} / 2$, what Nāgārjuna is saying is that moving is not an inherent property of a mover, and rather is a property of the interaction and relationship between the mover and its movement. Emphasis on interaction and relationality demonstrates the central purpose of MMK, which is to explicate śunyatā.

As we have seen, validity of the inner interpretations is dependent on validity of the outer. If they are fallacious, as I argue, then we are left with the next interpretation as the one that seems more than likely to represent what is actually being attempted by both Nāgārjuna and Zeno.

\subsection{SECRET INTERPRETATION CLUSTER}

The third, soteriological, or what I call the 'secret' interpretation, involves personal psychological and/or spiritual journey. In order to examine the secret interpretation, we need to step over or beyond purely rational, logical and scientific analysis to view the ultimate context of the authors' purpose. In other words, we have to examine our own experience in our own journey, and we have to examine it non-conceptually. In this view, we take the stance that Nāgārjuna and Zeno were not strictly philosophers and logicians, but rather additionally were meditation masters in their respective traditions, a claim I discuss below. As such, all of their rational analysis has a purpose that is not purely rational or even philosophical or intellectual, but rather is explicitly designed to assist fellow travelers on a path towards what some might call liberation (moksa) or enlightenment. Enlightenment, in this context, is more descriptively called discovery of the true and ultimate nature of our own minds: what is called the pristine state that embodies mindfulness and awareness (smrti), spontaneous presence, and direct, non-conceptual experience. In order to understand this interpretation cluster, we must be meditation students.

In those 'shamanic-spiritual-mystical traditions', or simply in Buddhist mahamudra, as an example, it is acknowledged that direct experience is not conceptual, that such direct experience embodies knowledge, thus use of concepts is laden with metaphor, analogy, simile, action, interaction, poetry, koans, meditation and art designed to point the student towards awakenment to the mystery of being that cannot be described in words.

The secret interpretation cluster pertains to the affect that Zeno's and Nāgārjuna's arguments have on people who are on a personal, experiential journey of meditation and discovery. It is because of this that our paucity of documentation supporting the claim that they were spiritual masters is not relevant. For Nāgārjuna, it is sufficient 
that the living teachers say that he was one, hence the words of the MMK are verbally taught to have the motivation and import that a spiritual master would embody, e.g. compassion and wisdom. For Zeno, we have documentation that he was a major student, if not the direct disciple of Parmenides, and that Parmenides was a spiritual master. Hence, if it is possible to interpret the paradoxes as the words of a spiritual master, it makes sense to do so.

This soteriological interpretation cluster is not quite as connected to the spacetime aspect of the outer interpretation cluster as interpretations in the other two clusters, hence not quite as susceptible to dismissal in the modern context. In the secret interpretation, 'motion' refers to motion of mind, which is a 'movement' of thoughts and emotions. Denial of motion then becomes acknowledgement of innate stability of mind. This stability or stillness is discovered in calm abiding (śamatha) meditation, which results in mindfulness - being present and attentive to the body in space and time, and to the passing ebb and flow of movement of mind manifesting as thoughts or emotions. Stability is not a state of having no thoughts, but rather is a state of not being distracted by thoughts or emotions. Such distraction manifests when we follow thoughts into elaborate stories of life unrelated to the present moment, such as in regret about the past, anticipation about the future, or in philosophic contemplation.

How does the philosophical presentation of motion by Zeno and Nāgārjuna relate to mental stability achieved in personal journey? One possible answer is that once motion and the inherent nature of phenomena are denied, and/or absurdity is determined from all attempts at rational understanding of how motion could exist, such as presented by both authors, and we realize the emptiness (śünyatā) of all phenomena, we would then give up attachment to language, concepts, and conceptual knowledge altogether in order to walk a path to realization of non-conceptual gnosis, the non-dual wisdom ( $\operatorname{rraj} \tilde{n} \bar{a})$ that directly 'sees' śünyatā, the empty nature of all phenomena.

This soteriological interpretation requires only that the recipient of the teachings drop her attachment to rationality, logic, abstract analysis and science in order to reach into her mind, heart and body to obtain direct instructions on the nature of reality derived from her own experience (the 'Goddess', the mother prajñāpāramitā, the wisdom that 'sees' śünyatā). Yet, there is still some dependence on being convinced, by the lack of a consistent logic, that logic is not sufficient to complete knowledge. These arguments are not convincing to scientifically sophisticated modern audiences.

In an alternate one of the interpretations in this cluster, Zeno and Nāgārjuna are using logic as a koan technique to demonstrate the limits of logic. They set up a problem that cannot be solved by logic-like asking for the sound of one hand clapping, or in this case how motion could exist when the object is always in one spot at any one time. The purpose is to suggest that some questions cannot be answered with concepts, logic and rational analysis. A koan has no purpose to convince us of anything. It is designed to stop our thinking mind. That mind can start up again with rational responses of at least two kinds: by stating that the question is absurd, or by 
finding a rational answer such as the fingers hammering the palm to make a sound of one hand clapping, or by explaining motion with mathematical physics. Yet, that is not the point of a koan. The koan has the purpose to introduce us to our original mind that exists prior to rational analysis. Then, through extended meditation, we look closer and might discover non-conceptual wisdom.

In the first interpretation of this cluster, we must have confidence, even certainty, in the logic that demonstrates the absurdity of applying logic to all problems. Only then will we have full confidence in the view that enables us to open our mind in order to directly perceive the true nature of reality. This confidence arises in different minds through different processes: some use philosophy and science; some reject one or both and instead use devotion alone. Devotion is an easier path, and koans are designed to assist students on that path.

\section{CONCLUSION}

Zeno's paradoxes are usually interpreted as a critique of generic change in a pluralist worldview. They do so using examples of spatio-temporal motion of physical objects. Such motion was not explainable 2400 years ago, resulting in the belief that motion, or more generic change, and pluralism generally, was perhaps problematic and perhaps illusory. I examined only The Arrow.

Nāgārjuna's MMK/2 addresses similar problems with similar arguments and conclusions, although since we have many verses in the context of a large, ancient text and many commentaries in several languages we also have many more and diverse interpretations.

I identified several interpretations of $M M K / 2$ and categorized them in three clusters. The outer pertains to change of physical things or generic change. The inner pertains to properties and nature, e.g. inherent nature, and semantics. The secret pertains to a personal, spiritual, experiential path of meditation.

I argued that the outer interpretation cluster was incoherent in a modern, $21^{\text {st }}$ century context of analytic philosophy and science. I also argued that many other interpretations were incoherent because they depended on coherence of the outer. We are left with the secret. In this cluster, both Nāgārjuna and Zeno are considered to be meditation masters, MMK/2 and Zeno's Arrow are both koans designed to stop the

mind from fixation on logic and concept, rather than being rational explications using logic and analytic philosophy.

\section{ACKNOWLEDGEMENTS}

Thanks to Josephine Spilka for turning me on to Peter Kingsley, whose research and views on Parmenides pulled everything together; to participants at the Dalhousie University philosophy colloquium and the 2016 Mind and Life Institute for constructive feedback; to Jay Garfield for fighting me tooth and nail, and advising me on writing style, both forcing me to achieve a level of clarity I would not have 
achieved otherwise; and to the two anonymous reviewers at Comparative Philosophy for requesting more clarity on my descriptions of rationality, truth, koan, and the place of koans and experience in the philosophical project altogether. Finally, thanks to the many lamas who tried to teach me mādhyamaka and mahamudra over these many decades: your perseverance in the face of stubbornness inspires me.

\section{REFERENCES}

Alexander, Amir (2014), Infinitesimal: How a dangerous mathematical theory shaped the modern world (New York: Scientific American, Farrar, Straus and Giroux)

Analytic philosophy. (2017, May 26). In Wikipedia, The Free Encyclopedia. Retrieved 12:41, June 16, 2017, from <https://en.wikipedia.org/w/index.php? title=Analytic_philosophy\&oldid=782314197>.

Aristotle Physics, Book VI, chapter 9 lines 5-9.

Arnold, Dan (2012), “The deceptive simplicity of Nāgārjuna's arguments against motion: Another look at Mülamādhyamakakārikā Chapter 2", Journal of Indian Philosophy, 40: 553-501.

Bhattacharya, Kamaleswar (1980-81), “The Grammatical Basis of Nagarjuna's Arguments: Some Further Considerations", Indologica Taurinensia, 8-9: 35-43.

Brumbaugh, Robert S. (1964), The Philosophers of Greece (New York: Thomas T. Crowell Co.)

Bub, Jeffrey (1997), Interpreting the Quantum World (Cambridge: Cambridge University Press).

Cao, T. Y. and Schweber, S. S. (1993), "The Conceptual Foundations and the Philosophical Aspects of Renormalization Theory", Synthese 97.1: 33-108

Cao, Tian Yu. (1997) Conceptual Developments of 20th Century Field Theories (Cambridge: Cambridge University Press).

Cao, Tian Yu. (1999) Conceptual Foundations of Quantum Field Theory (Cambridge: Cambridge University Press).

Code, Murray J. (1982), “Zeno's Paradoxes I: The standard mathematical response”, Nature and System 4: 45-58.

Conze, Edward (1962), Buddhist Thought in India (London: Allen and Unwin).

Conze, Edward (1963), "Buddhist Philosophy and its European Parallels", Philosophy East and West 13.1 (Apr., 1963): 9-23.

Dorje, Wangchuk, The Ninth Karmapa (2001), Mahāmudrā: The Ocean of Definitive Meaning (Seattle: Nitartha International).

Ganeri, Jonardon (2015), "Analytic Philosophy in Early Modern India", The Stanford Encyclopedia of Philosophy (Summer 2015 Edition), Edward N. Zalta (ed.): $<$ https://plato.stanford.edu/archives/sum2015/entries/early-modern-india/>.

Garfield, Jay L. (1995), The Fundamental Wisdom of the Middle Way: Nāgārjuna's Mūlamadhyamakakārikē Translation and Commentary by Jay L. Garfield, (Oxford: Oxford University Press). 
Galloway, B. (1987), Notes on Nāgārjuna and Zeno on motion, Journal of the International Association of Buddhist Studies 10: 81-87.

Grünbaum, Adolf (1967), Modern Science and Zeno's Paradoxes (Middletown, Connecticut: Wesleyan University Press).

Gyamtso, Khenpo Tsültrim (2003), Sun of Wisdom (Boston \& London: Shambhala). de Jong, J. W. (1972), "Emptiness", Journal of Indian Philosophy 2: 7-15.

Hayes, Richard (1994), "Nāgārjuna's appeal”, Journal of Indian Philosophy 22: 299378.

Hawking, Stephen (2014/1966), "Singularities and the geometry of spacetime" European Physical Journal H, (Nov. 2014) 39 (4).

Hopkins, Jeffrey (1996), Meditation on Emptiness (revised edition) (Somerville, MA.:Wisdom Publications).

Kalupahana, David J. (1986), The Philosophy of the Middle Way (Albany: SUNY Press).

Kapstein, Matthew (1988), "Mereological Considerations in Vasubandhu's 'Proof of Idealism', Idealistic studies 18.1 (January 1988): 32-53.

Kingsley, Peter (2003), Reality (Inverness, California: Golden Sufi Center Publishing).

Lombardo, Stanley (1982), Parmenides and Empedocles (Berkeley, CA: Grey Fox Press).

Mabbett, Ian. (1984), "Nāgārjuna and Zeno on motion", Philosophy East and West, 34.4: 401-420.

Mabbett, Ian (1998), "The Problem of the Historical Nāgārjuna Revisited”, Journal of the American Oriental Society 118.3 (Jul. - Sep. 1998): 332-346.

Mazur, Joseph (2007), The Motion Paradox (New York: Dutton).

McEvilley, Thomas (1981), "Early Greek philosophy and Madhyamaka", Philosophy East and West 31.2: 141-164.

McEvilley, Thomas (1982), "Pyrrhonism and Madhyamika", Philosophy East and West 32.1: 3-35.

McEvilley, Thomas (2002), The Shape of Ancient Thought (New York: Allworth Communications).

McTaggart, J.M.E. (1908), "The Unreality of Time”, Mind 17 (68): 457-74.

McTaggart, J.M.E. (1927), The nature of existence Vol. 2 (Cambridge: Cambridge University Press).

Padmakara Translation Group, tr. (2005), Adornment of the Middle Way: Śäntarakșita's Madhyamakalankara with Commentary by Jamgön Mipham (Boston: Shambhala Press)

Palmer, John (2016), "Parmenides", The Stanford Encyclopedia of Philosophy (Winter 2016 Edition), Edward N. Zalta (ed.): < https://plato.stanford. edu/archives/win2016/entries/parmenides/>.

Palmer, John, "Zeno of Elea", The Stanford Encyclopedia of Philosophy (Spring 2017 Edition), Edward N. Zalta (ed.), forthcoming <https://plato.stanford.edu/ archives/spr2017/entries/zeno-elea/>. 
Paul, Robert Alan (2013), The Philosophy and Physics of Relationality and Inherent Nature: Súnyatā and Svabhava in Madhyamaka Buddhist philosophy, Western Analytic Metaphysics, Philosophy of Science and Physics. Ph.D. Dissertation, (Halifax, NS: Dalhousie University): <http://dalspace.library.dal.ca:8080/ bitstream/handle/10222/21733/Paul-Robert-PHD-IDPHD-April-2013.pdf?

Sequence $=3 \&$ isAllowed $=\mathrm{y}>$.

Paul, Robert Alan (2016a), Buddhism and Modern Physics, Volume 1: Non-Technical Summary Independently Published through Amazon.

Paul, Robert Alan (2016b), Buddhism and Modern Physics, Volume 2: Scholarly Edition Independently Published through Amazon.

Real, (2011), In Merriam-Webster.com, retrieved May 27, 2017, from <https:// www.merriam-webster.com/dictionary/hacker>.

Rospatt, Alexander von. (1995), The Buddhist Doctrine of Momentariness (Stuttgart: Franz Steiner Verlag).

Ruegg, David Seyfort (2000), Three Studies in the History of Indian and Tibetan Madhyamaka Philosophy Arbeitskreis für Tibetische und Buddhistische Studien, (Wien: University of Wien).

Russell, B. (1961), History of Western Philosophy (London: George Allen \& Unwin).

Russell, B. (1929), Our Knowledge of the External World, (New York: W. W. Norton).

Salmon, W. C. (ed.) (1970), Zeno's Paradoxes (Indianapolis and New York: BobbsMerrill).

Siderits, M. and O’Brien, D. J. (1976), “Zeno and Nāgārjuna on Motion”, Philosophy East and West 26.3: 281-299.

Siderits, Mark and Shōryū Katsura (2013) Nāgārjuna's Middle Way: MūlaMādhyamakakārikā (Somerville, MA: Wisdom).

Sprung, M. (trans.) (in collaboration with T. R. V. Murti \& U. S. Vyas) (1979), Lucid Exposition of the Middle Way: The Essential Chapters from the Prasannapada of Candrakirti (London: Routledge and Kegan Paul).

Taber, John A. (1998), "On Nāgārjuna's so-called fallacies: A comparative approach", Indo-Iranian Journal 41: 213-244.

Tenzin, The Third Khamtrul Rinpoche, Ngawant Kunga Tenzin (2014), The Royal Seal of Mahamudra (Boston: Snow Lion).

Thakchoe, Sonam (2007), The two truths debate: Tsongkhapa and Gorampa on the Middle Way (Somerville, MA: Wisdom).

Thrangu, Khenchen, Rinpoche (2003), Pointing out the Dharmakaya (Ithaca: Snow Lion).

Thrangu, Khenchen, Rinpoche (2004), Essentials of Mahamudra (Somerville: Wisdom).

Tillemans, Tom, (2011/2014), "Dharmakīti", The Stanford Encyclopedia of Philosophy (Spring 2014 Edition), Edward N. Zalta (ed.): <http://plato.stanford. edu/archives/spr2014/entries/dharmakiirti/>.

Vasubandhu (1988-90), Abhidharmakosabyasyam Louis de la Vallee Poussin trans. to French, Leo M. Pruden trans. to English. (Berkeley: Asian Humanities Press). 
Westerhoff, Jan (2009), Nāgārjuna's Madhyamaka: A Philosophical Introduction (Oxford: Oxford University Press).

Wheelwright, Philip ed. (1966), The Presocratics (New York: Odyssey Press). 